\title{
La retórica de deudas, vínculos y deberes en algunas cartas de mujeres medievales
}

\section{Rhetoric of Debts, Linkages and Duties in Medieval Women's Letters}

\author{
Pilar Valero-Costa \\ University of California, Fullerton \\ pvalero-costa@fullerton.edu
}

El artículo analiza los temas y las estrategias retóricas de escritura de cartas escritas, o dictadas, por mujeres medievales, motivadas por la ausencia o distancia del esposo o del amante. El trabajo analiza tres conjuntos de cartas, las de Héloise, una de las grandes abadesas del siglo XII, que sufre el descuido de su esposo, el filósofo Pierre Abélard; las de Sereneta, barcelonesa burguesa, que requiere constantemente la presencia de su marido Ramón de Tous; empleado de la condesa de Xérica en el siglo xIV; y el de Margaret Paston, perteneciente a una familia reconocida de Inglaterra en el siglo Xv, cabeza del hogar en ausencia de su esposo John. El análisis se limita al examen textual del concepto del deber entre esposos, y los recursos retóricos empleados por estas tres mujeres en la interacción con el ausente. Además de su interés intrínseco, las cartas ayudan, sin duda, a reconstruir las costumbres, el pensamiento y las relaciones humanas de aquel momento.

Palabras clave: retórica, cartas, escritura, mujer, Eloísa, Abelardo, Sereneta, Ramón de Tous, Margaret Paston, deuda, deber conyugal

The paper analyzes the topics and the rhetoric strategies used in Medieval letters written, or dictated, by women whose husbands or lovers are away from home. The paper studies three sets of letters: from Héloise to Abélard, a Medieval French woman, from Sereneta to Ramón de Tous, a Catalan woman, and from Margaret Paston, an Englishwoman. The analyse focuses on the concept of debt between the couple. These letters, besides their intrinsic interest, shed light on the quotidian Medieval customs and manners, thought, and human relationships in that period.

KeYwords: rhetoric, letters, writing, woman, Héloise, Abelard, Sereneta, Ramón de Tous, Margaret Paston, debt of couple 
A juzgar por la cantidad de cartas escritas en la Edad Media que han sobrevivido en archivos y bibliotecas familiares o nacionales, es necesario asumir que serían miles las que se escribieron y que muchas se extraviaron con las vicisitudes inexorables del paso del tiempo. Además, es posible pensar que debido a la lejanía temporal, los mensajes que se pueden dilucidar de las cartas llegadas a nuestras manos hayan perdido mucho de su intencionalidad original. Sin embargo, estos mensajes, una vez descifrados del texto escrito, iluminan la oscuridad producida por la distancia y nos ayudan a reconstruir las costumbres, el pensamiento y las relaciones humanas de aquel momento. Aunque sea imposible recuperar en su totalidad el momento histórico en el que se escribieron las cartas, el estudio detallado de los textos nos aproxima, aunque ciertamente de manera no real, a la vida de aquel momento. Además, la escritura de las cartas nos produce un efecto de presencia y cercanía que, como bien dice Héléne Cixous, borra toda separación. La palabra escrita imbuida de la intención de quien la escribe transmite el mensaje deseado y acerca al ausente (Entre l'écriture, 13).

Son muchas las cartas escritas y muchos los mensajes que de ellas se podrían dilucidar. Según Joan Ferrante:

The letters offer a counter to the misogynist texts and help recreate to some extent medieval women's complicated sense of woman's place in the world on the one hand, frequently hearing how weak and dangerous women were, how unfit, indeed forbidden, to rule or to teach; on the other, seeing women in positions of authority $[\ldots]$ (To the glory, 11).

Limitando el examen textual al tema específico del concepto del deber entre esposos, me propongo estudiar una pequeña muestra del vasto legado que ha llegado a nuestras manos: algunas cartas dirigidas a sus maridos ausentes, escritas unas, dictadas otras, por esposas que se sintieron abandonadas o de alguna manera desatendidas y relegadas a la esfera privada. Este es el caso de Héloise, una de las grandes abadesas del siglo XII, que sufre el descuido de su esposo, el filósofo Pierre Abélard; el de Sereneta, barcelonesa burguesa, que requiere constantemente la presencia de su marido Ramon de Tous; empleado de la condesa de Xérica en el siglo XIV; y el de Margaret Paston, perteneciente a una familia reconocida de Inglaterra en el siglo XV, cabeza del hogar en ausencia de su esposo John. Las cartas nos brindan la oportunidad de atisbar y rescatar una voz femenina, que emerge encerrada en elementos autobiográficos, pero que bien podría ilustrar la voz de cualquier mujer casada del medioevo perteneciente a un estrato social de privilegio, 
siempre dentro de las convenciones sociales de la época. Además, las cartas reafirman la percepción y la apreciación de la vida de las mujeres casadas destinadas a permanecer en la esfera privada esperando siempre el regreso del marido. Al mismo tiempo, ilustran el concepto del deber y las obligaciones a las que se sometían los cónyuges al contraer matrimonio. El concepto queda expresado de una manera clara en las palabras de San Pablo a los Corintios: "Que el marido dé a su mujer lo que debe y la mujer de igual modo a su marido." (1 Cor. 7,3). Y la responsabilidad específica de los maridos para con las esposas está ilustrada, también por San Pablo, cuando escribe a los Efesios: "Así deben amar los maridos a sus mujeres como a sus propios cuerpos. El que ama a su mujer se ama a sí mismo” (Eph. 5, 28).

Las tres mujeres reclaman la presencia del marido en sus cartas, sin embargo, existe una gran diferencia entre las de Sereneta y Margaret con las de Héloise. Mientras que las cartas en lengua vernácula de las dos primeras son cortas, generalmente dictadas, que se concentran en temas relacionados a la esfera secular cotidiana de una manera clara y directa, las de Héloise, escritas en latín, son largas y muestran una compleja elegancia retórica espejo de una personalidad excepcional. Por eso me he tomado la libertad de cambiar el orden cronológico para el estudio de los textos. Empezaré examinando las cartas de Sereneta, que reflejan un amor desgarrado e impaciente, plagado de celos. Luego trataré las de Margaret Paston, que a pesar de referirse a las necesidades cotidianas, muestran un dulce amor ávido de la presencia física del marido para su nutrición. Al fin, trataré solo las dos primeras de Héloise, que según Betty Radice "are representative of the best of their time" ("Heloise", 9) ya que expresan un profundo conocimiento clásico en tratar un dilema que carece de tiempo: el del amor.

El concepto de la deuda entre esposos en la esfera secular y cotidiana está representado en las cartas de Sereneta, para la que el matrimonio tiene una vertiente principal, la del amor y los vínculos que representa. Sereneta, acuciada por el poder del amor, rompe las barreras del silencio y se proyecta en las cartas como una mujer que reclama sus derechos, sin miedo. Hay que tener en cuenta que las cartas de Sereneta son cartas dictadas y en esto cabe la posibilidad de que el escriba hubiera cambiado algunas palabras y hasta incluso la sintaxis y la construcción de la carta (Deyermond, "Letters as Autobiography”, 36). Sin embargo, la constante repetición, la apremiante llamada al marido ausente nos presenta una personalidad y una voz femenina atrapada en los vínculos del matrimonio, como amor legalizado, un amor tintado por los celos en algunas ocasiones, que no tiene reservas en expresar su deseo. Es un amor sin límites que está más allá de la prudencia y del miedo al ridículo. 
Por eso Sereneta dicta desde abril de 1374 hasta abril de 1376, trece cartas dirigidas a su marido, que estaba fuera ocupándose de los negocios de la condesa a quien servía (Deyermond, "Letters as autobiography", 37).

Las mujeres en la Edad Media, respondiendo a la imagen, diseñada para ellas por una sociedad misógina, son las responsables primarias del buen funcionamiento interno del hogar cuando el marido está ausente: "[ ... ] for everybody knows that the lady is responsible for the household and that she means what she says" (Pitts, The fifteen joys, 34). Por eso Sereneta en sus cartas siempre trata en primer lugar algunos temas económicos y cotidianos referentes al funcionamiento del hogar, a la carencia de alimentos, a proyectos futuros o a las visitas de algunos conocidos, para pasar después a los asuntos personales y a los reproches. "If the lay view of medieval woman was a scold and a shrew, it may be because scolding was her only recourse against subjection to man, a condition codified like everything else by Thomas Aquinas" (Tuchman, A distant mirror, 214).

Las cartas de Sereneta, escritas en catalán, su lengua vernácula, carecen de brillantez retórica, son cortas y van directamente a los asuntos a tratar. No utiliza ninguna imagen ni estrategia sutil para comunicar lo que quiere. Se conforma con la táctica directa y repite al marido una y otra vez el deseo que tiene de verlo y la necesidad de su presencia. Por ejemplo, en la carta de abril de 1374 dice: "E perch-vos que per la bona amor qui és entre vós e me [...]" (406). ${ }^{1}$ En la carta de junio del mismo año: "con si vós, sényer, sabíeu l'ánsia e el desigt que jo he de vós, vós sényer, m’escriuríeu [...]” (408). Cuando se siente de alguna manera desesperada y olvidada como en la carta que le escribe en el mes de abril de 1375, dice; “[... que pus que vós no volets venir a mi, jo hiré a vos, i trobareu-hi, sényer [...]” (414).

En otras cartas, Sereneta pide a su esposo, su presencia al menos a través de la escritura, algo que le traiga noticias de que está bien y que le dé la esperanza de su pronto regreso. Como bien dice Cixous, nosotros los humanos podemos proyectarnos en la escritura para liberarnos del miedo y soledad que nos acosa y para acercarnos al ser querido (Cixous, Entre l'écriture, 26). En la carta fechada el 22 de abril de 1375 dice: "[... ] me maravell molt co no m'escrivis, cor jo son certa que tots dies entren gens an Barcelona $[\ldots]$ ” (414). Sería fácil para el marido poner unas letras con algunos de los conocidos que a menudo viajaban a Barcelona desde Aragón donde él estaba. El 15 de enero de 1376 le vuelve a escribir y en esta ocasión le cuenta que está

${ }^{1}$ Cartas en "Cartes d'una Catalana del siglo xIV al seu marit”, 387-419. En adelante solamente indico el número de página. 
sana, pero muy triste porque "neguna letra vostra no he aüda [...]" (415). El 20 de marzo del mismo año, Sereneta insiste en la necesidad que tiene de recibir noticias, "molt me maravel de vós, senyer, con tant a tart m'escrivis [... ]" (416).

Si tenemos en cuenta que las cartas fueron dictadas, es posible suponer que el escriba se hubiera reído o hubiera comentado después con su familia o sus amigos la insistencia de Sereneta. Pero este detalle no la reprime ni la hace abandonar su empeño. Además, a pesar de ser una esposa relegada a la esfera privada no tiene miedo de reprochar la ausencia y sin temor deja aflorar sus celos. En la carta del 21 de septiembre de 1374 Sereneta dice al esposo: "Adés, senyer, no sé als que us faça saber si no que Déu vos dó salut e amor de dones jóvens d'Aragó” y al mes siguiente vuelve a insistir: “[... ] que us faça a saber si no que Déu vos dó salut e amor des dones d'Aragó” (408). La insistencia y las demostraciones de celos de alguna manera confirman la idea que se tenía de la mujer en el Medievo. A pesar de que Sereneta, mujer fuerte y segura de sí misma, no deja pasar ninguna oportunidad de recordar al marido de sus obligaciones para con ella, el tono que utiliza es amigable y conciliatorio, sin perder nunca el respeto.

$\mathrm{Al}$ igual que Sereneta de Tous, Margaret Paston, esposa diligente y fiel, relata en sus cartas los avatares cotidianos del funcionamiento del hogar. Ella escribe a su marido "asking advice, giving news, rendering accounts" (Woolf, “The Pastons”, 7). Sin embargo, Margaret añade un nuevo matiz, una táctica algo diferente que recuerda al esposo sus obligaciones. De la misma manera que Sereneta, ella suplica, como sujeto independiente, la presencia del marido, pero, además, le pide regalos, vestidos, telas, y corsés como excusa para que regrese. Por ejemplo, en diciembre de 1441, Margaret escribe: "[... ] for I have no gown to wear this winter but my black and my green a lierre, and that is so cumbrous that I am weary to wear it [... I I pray you, if ye dare take it upon you, that ye will wouchsafe to do make it against ye come home; for I had never more need thereof than I have now, for I am wax so fetis that I may not be girt in no bar of no girdle that I have but of one" (4). En la misma

\footnotetext{
2 “[ [.. ] solo tengo un vestido para ponerme en este invierno, el negro y verde, y es tan pesado que estoy cansada de ponérmelo... Le suplico, si se atreve a hacerlo, si me hiciera el favor, que vuelva a casa; ya que nunca he tenido más necesidad de usted que tengo ahora, porque estoy engordando tanto que nada me cabe ya, no quepo en ninguna faja y solo tengo una" (4). La traducción de este pasaje y todos los subsiguientes son de la autora. Las cartas están tomadas de The Paston Letters, ed. de Norman Davis, 4-5, 13-14, 21, 34-36, 55. En adelante solamente se indica el número de página.
}

Medievalia 50, 2018, pp. 261-273 
carta, como un broche de oro, le pide que la tenga presente en el anillo que ella le regaló y al mismo tiempo con extrema sutileza expresando "the disconnforts of her first pregnancy" (Deyermond, "Letters as autobiography”, 34) le exige que no la olvide: "I pray you that ye will wear the ring with the image of Saint Margaret that I sent you for remembrance till ye come home. Ye have left me such a remembrance that maketh me to think upon you both day and night when I would sleep" (5). ${ }^{3}$ En 1448, cuando la casa de los Paston está siendo sitiada y la carencia de alimentos es grave, Margaret escribe a John que está en Londres para encargarle todo lo difícil de obtener: "I pray you that ye will vouchsafe to by for me $1 \mathrm{lb}$. of almonds and $1 \mathrm{lb}$. of sugar" (14), y con mucha astucia, incluye la necesidad de los hijos, que están sin ropa, para que el esposo sienta la premura de la obligación: “[ ... that ye will do buyen some frieze to maken of your childer's gowns" (14). ${ }^{4}$

En abril de 1453, cuando se ha consolidado la posición de la familia Paston, Margaret, consciente de su estatus social y respondiendo a la concepción frívola que ya en la Edad Media se tenía de las mujeres, escribe pidiendo a John algunos abalorios propios de su clase, que la adornen con elegancia, cuando tenga que ir a una fiesta. Se queja de que ya ha tenido que usar el collar de su prima en la visita de la reina: "I pray you that ye will do your cost on me against Whitsuntide, that I may have something for my neck. When the Queen was here I borrowed my cousin Elisabeth Clere's device, for I drust not for shame go with my beads among so many fresh gentlewomen as here were at that time" $(36) .^{5}$

Según Virginia Woolf, Margaret Paston nunca se presenta como una heroína en las cartas ("The Pastons", 6), sin embargo, aunque siempre relegada a la esfera del hogar, es evidente que está preocupada por sí misma como sujeto independiente y que no tiene miedo de airear sus necesidades y recordar al marido sus obligaciones. Por eso su voz, al igual que la de Héloise y la de Sereneta, invierte de alguna manera la concepción de la mujer sumisa que espera con paciencia el regreso de su esposo.

\footnotetext{
3 "Le suplico que lleve siempre puesto el anillo con la imagen de Santa Margarita que le envíe para que me recuerde hasta que regrese a casa. Usted me ha dejado un recuerdo tan grande que me hace pensar en usted día y noche cuando intento dormir” (5).

4 "Le suplico, si me hace el favor, que me compre una libra de almendras y otra de azúcar [... $]$ y que me compre algo de tela para hacer vestidos a sus hijos” (14).

5 "Le suplico si puede comprarme algo para Pentecostés de manera que tenga algo para el cuello. Cuando al Reina estuvo aquí mi prima Elisabeth me dejó su collar, ya que no me atrevía, por vergüenza, a usar mis bolitas delante de tantas damas elegantes que habían aquí en aquella ocasión" (36).
} 
Una vez establecida la obligación de John para con ella y con sus hijos, Margaret recurre al vínculo del amor y la admiración por el ser querido. Si para una mujer es importante tener ropa elegante que la pueda representar como un miembro de su estamento social, es más necesario tener cerca a su esposo: “[...] I would ye wern at home, if it were your ease and your sore might been as well looked to here as it is there ye been now, liefer than a new gown, though it were scarlet" (7). ${ }^{6}$ De esta manera eleva la necesidad de la presencia de la persona del marido a una esfera superior. No hay peor situación que la de sentirse viuda cuando una mujer añora a su esposo, por eso Margaret apela al sentido de compasión de John, al decirle en la carta del 24 de diciembre de 1459: "I am sorry that ye shall not at home be for Christmas. I pray you that ye will came as soon as ye may; I shall think myself half a widow because ye shall not be at home $[\ldots]^{\prime \prime}(55) .^{7}$

Es conocida la desgraciada historia de amor de Héloise y Abélard, una historia contada en la correspondencia que mantuvieron durante muchos años (Radice, "Heloise”, 9). Héloise, una joven ávida de saber, fue discípula de Abélard primero, para convertirse poco después en su enamorada y amante. Las circunstancias los obligaron a un matrimonio clandestino al que Héloise se oponía. Poco después Abélard la obligó a que tomara los hábitos, seguramente para protegerla de Fulbert, el tío de ella. Las consecuencias de esto fueron desastrosas, ya que Fulbert pensando que Abélard quería librarse de Héloise haciéndole profesar, tomó la venganza por su mano y una noche mandó castrar a Abélard. Éste, desesperado, desapareció de la presencia de la esposa monja durante unos diez años.

Héloise, la joven esposa-monja, es reconocida como una de las grandes abadesas del siglo XII, tanto por su conocimiento de la literatura clásica como por su dominio del latín, el griego y el hebreo (Radice, "Heloise”, 93). Sus cartas están dirigidas a Pierre Abélard, el esposo ausente del que continúa perdidamente enamorada. Por esta razón, escribiendo en latín, utiliza para su propósito, técnicas y estrategias que a primera vista pudieran parecer discretas e inocentes, pero que en realidad responden a una intención premeditada y calculada: Héloise necesita por amor y exige por legitimidad la presencia de Abélard. Está dispuesta a hacer valer sus derechos como amante y esposa, a recordar al marido ausente las obligaciones contraídas, si no por el voto

6 "Me gustaría que estuviera usted en casa, donde pudiera cuidarle y sanar su herida mejor que donde ahora está, (esto me gustaría más) que un vestido nuevo aunque fuera escarlata" (7).

7 “Tengo pena de que no vaya a estar aquí para Navidad. Le suplico que venga lo más pronto posible; me imagino que soy medio viuda, porque no va a estar en casa” (55).

Medievalia 50, 2018, pp. 261-273 
matrimonial, al menos en nombre del gran amor que los unió. Y si Abélard no pudiera visitarla en persona, Héloise exige su presencia a través de la escritura. La voz a través de la escritura no tiene límites y es capaz de atravesar el infinito hasta alcanzar su cometido. Por eso, Héloise exige la presencia de Abélard, al menos en forma de respuesta en una carta. De esta manera ella podrá recuperar a su amado en el texto escrito y mantenerlo siempre con ella.

Sus dos primeras cartas se han considerado por los estudiosos como una de las muestras de la retórica más brillante de la literatura, además de ser las más íntimas (Kamuf, Fictions, 110). Estas cartas tratan de su amor por Abélard. En su primera carta Héloise demuestra en la manipulación de las palabras una extremada sutileza y un profundo conocimiento de la lengua. $\mathrm{Su}$ maestría es evidente en el sistema de jerarquía que concibe entre las deudas y los vínculos de Abélard y el modo en el que éstos crean unos deberes y obligaciones de los que el ausente no podrá escapar.

Dirigiéndose a su adorado esposo, Héloise le recuerda primero las ataduras que lo unen a ella y con un movimiento ascendente convierte los vínculos en deudas y las deudas en obligaciones que atrapan a Abélard. Esta progresión es evidente, además, en las diferentes relaciones que Héloise trata en la carta, relaciones que cubren una amplia gama, pasando desde la amistad a la de padre espiritual, a la de marido. Además, especifica los compromisos y responsabilidades que cada una de estas relaciones lleva consigo. El objeto primordial de este movimiento ascendente y progresivo es hacer que Abélard reconozca como un deber ineludible lo que Héloise le pide. Para conseguir este propósito, Héloise construye una estrategia retórica en la que primero halaga a Abélard para atraer su atención, alabanzas que se convierten en acusaciones una vez conseguido el interés.

El primer establecimiento de compromiso lo toma Héloise del tema de la Historia calamitatum. Según Peter Dronke, es evidente que Héloise escribió la primera de sus cartas después de haber leído la Historia calamitatum, escrita por Abélard, para consolar a un amigo de sus penas y calamidades, contando sus propias desgracias y sufrimientos (Women writers, 113). Al principio de la carta, Héloise halaga a Abélard por haber cumplido su promesa: "Complesti revera in epistola illa quod in exordio ejus amico promisisti, uit videlicet in comparatione tuarum suas molestias nullas vel parvas reputaret" (Abélard, Opera, 72). ${ }^{8}$ Pero esta alabanza está concebida con mucho cuidado con el

8 "En aquella carta si cumpliste la promesa que le hacías a tu amigo al principio de la misma, que pensara que sus problemas eran insignificantes o que no existían, en comparación con los tuyos" (72). 
propósito de manifestar cómo una relación, en este caso la amistad, genera una obligación: "Morem quidem amico et socio gessisti, et tam amicitiae quam societatis debitum persolvisti; sed majore te debito nobis astrinxisti [... ]" (73). ${ }^{9}$ De esta manera Abélard se ha condenado a sí mismo, por sus propias acciones. Si él mismo reconoce que está comprometido a cumplir la promesa hecha a un amigo, ¿cuáles serán las obligaciones generadas por los vínculos que lo unen a Héloise, su propia esposa?

Si este caso no compromete a Abélard, Héloise le recuerda otro de sus deberes, el de fundador y creador del monasterio llamado el "Paraclete". Al leer la Historia calamitatum, nos damos cuenta que él fue el fundador de la abadía desde la que Héloise escribe. Cuando Héloise usa "nosotras" se está refiriendo a la comunidad de monjas que viven con ella. De nuevo, aquí la palabra deber está colocada en conjunción con la palabra deuda, una deuda que se convierte en algo más fuerte ya que era de todos conocida la responsabilidad que Abélard tenía con el convento. Abélard tiene que cumplir el compromiso creado por la obligación y no hay manera de que se escape de ella. Sin embargo, Héloise endulza este deber al recordarle que la obligación está basada en la superioridad y magnificencia de sus actos; lo elogia como el único fundador, el único constructor, el único edificador. ¿Cuál es el vínculo obligatorio que Abélard tiene con su nueva plantación? Si él es el único creador, el único responsable de la existencia del monasterio, si él es el jardinero que plantó nuevas semillas al fundar el Paraclete para gloria de Dios, por cierto tiene responsabilidades no solo materiales, sino también espirituales. Sería posible pensar que Héloise al hablar de semillas se esté refiriendo también a la semilla que fructificó en ella, el pequeño Astrolabio, que vive con la familia de Abélard (Radice, "Heloise", 92), para recordarle otras obligaciones y responsabilidades evadidas.

Además, las nuevas y tiernas semillas necesitan cuidado especial y dedicación, especialmente porque son "de naturaleza femenina." A pesar de que Héloise no es una mujer cobarde ni frágil, se aprovecha de la imagen y la representación femeninas para enfrentarse a Abélard y pedirle directamente que su obligación es cuidar de su "plantación." De nuevo Héloise utiliza el lenguaje como un arma, un arma que crea un deber y una obligación ineludibles por el compromiso que Abélard ha contraído con las delicadas semillas femeninas. Para dar autoría y validez a la imagen usada, Héloise recurre a las sagradas escrituras y a su vasto conocimiento de los Evangelios. Utiliza la

\footnotetext{
9 "Pagaste la deuda con tu amigo y compañero, eximiste tu deuda con la amistad y el compañerismo; pero estás ligado a nosotras con una mayor deuda $[\ldots]$ ” (73).
}

Medievalia 50, 2018, pp. 261-273 
carta de San Pablo a los Corintios, "Yo planté, [... ] más fue Dios quien dio el crecimiento" (74, de 1Cor. 3,6). Solo cuando el jardinero que la ha plantado cuide y mantenga con amor su plantación, solo cuando Abélard se preocupe de su fundación y reconozca sus deberes para con el monasterio, hará Dios que crezcan y florezcan las semillas plantadas.

Para enfatizar de nuevo los compromisos y obligaciones creados por la relación que Abélard tiene con Héloise y su comunidad de monjas, los contrasta con los deberes que Abélard tiene como abad: "Quid tuae debeas attende, qui sic curam impendis alienae" (74). De esta manera Héloise le recuerda que tiene que cuidar y consolar a sus hijas espirituales en lugar de dedicar todo su tiempo a la enseñanza.

Demostrando una gran sofisticación, Héloise eleva la discusión a otro plano. Un plano más íntimo que se refiere a su matrimonio con Abélard, un matrimonio al que ella se oponía pero que los vincula para siempre. Para conseguir este efecto, Héloise cambia el pronombre personal "nosotras", que se refería a las monjas, por el de "yo" que se refiere a sí misma y la relación personal de los dos, para exigirle que cumpla sus deberes como marido: "Atque ut caeteras omittam, quanto erga me te obligaveris debito, pensa" (74). La obligación de Abélard como esposo es mucho más fuerte que los deberes que tiene como fundador de la abadía, el vínculo personal es mayor que el colectivo.

Una vez establecido el vínculo personal y las deudas que tiene Abélard con Héloise, esta manipula el concepto del deber elevándolo a otro nivel que utilizará como una catapulta. Es interesante notar que guarda esta arma, el amor inconmensurable que siente por su adorado, como un golpe final, un golpe que añadirá en profundidad a la obligación de Abélard. Para Héloise, al igual que para Sereneta y Margaret, un amor inconmesurable crea un deber ineludible que está por encima de los vínculos del matrimonio. Es necesario aclarar que al amor de Héloise se ha incorporado un tremendo sacrificio, el sacrificio del cuerpo, el del deseo, el del cambio de vida profesando como postulante en el convento, que la condena a renunciar a la relación sexual con el hombre a quien ama sin medida. Si a esto se añade el hecho de que es el esposo, quien la obliga a llevar a cabo estos sacrificios, "meipsam pro jussu tuo perdere sustinerem" (75), es fácil de comprender que ella exija el cumplimiento de un deber de igual magnitud por parte de Pierre. De esta manera, Héloise llega al concepto de retribución —el deber está atado a la compensación, una compensación que solo Abélard puede proporcionar: "Et solus es qui plurimum id mihi debeas" (75). En esta parte de la carta están unidos magistralmente los conceptos de ser la causa de una profunda tristeza, la fuente de la consolación, el poder de traer alegría o desesperación, la deuda y la 
gratificación. Héloise espera de esta manera convencer a Abélard que acepte conscientemente el compromiso adquirido por el amor, aún sabiendo que la relación será solo platónica.

Héloise, con gran maestría, combina las palabras y los conceptos del deber, la obligación y la deuda para convencer a Abélard de que tendrá que pagar y recompensar el sacrificio hecho por ella. Crea un patrón de obligaciones para establecer una jerarquía de deudas todas dirigidas hacia ella. Sus referencias al matrimonio podrían verse como construcciones con dos vertientes. Una sería la deuda sexual a la que están obligados los miembros de la pareja, una deuda que Abélard no podrá nunca corresponder debido a su castración, y la otra se refiere a la unión espiritual que gozan los esposos.

Los textos de las tres mujeres tratadas en este artículo, a pesar de que pertenecen a esferas sociales, siglos y países diferentes, desarrollan una voz propia subjetiva y sincera, que define desde su punto de vista el concepto del deber entre esposos. Las tres se refieren a los mismos temas y tratan la ausencia del esposo como algo terrible que se tiene que subsanar. La pareja tiene que vivir unida, al menos en la correspondencia. Los esposos tienen una deuda que ellas les recuerdan con insistencia. Héloise, francesa del siglo XII, condenada a la castidad por la incapacidad del marido y por los votos religiosos, exige al menos la atención espiritual de su amado. Dos siglos después, la catalana Sereneta, acomodada en la burguesía naciente, se queja de la ausencia prolongada de su esposo con algunas pinceladas de celos. Margaret, británica perteneciente a una familia que ha conseguido encumbrase en el siglo Xv, se cuida del hogar de los hijos y de la suegra, al tiempo que reclama con sutileza el regreso de John.

Esta voz subjetiva, convertida en palabra escrita, ilumina la vida cotidiana en las esferas secular y religiosa y nos depara una cantidad innumerable de pequeños detalles vivenciales. Al estudiar las cartas de estas tres mujeres se recupera una voz femenina, que aunque encerrada en elementos autobiográficos bien podría ilustrar la de cualquier mujer casada del momento, perteneciente a una clase privilegiada. Además, se desenmascaran unas fuertes personalidades femeninas dispuestas a airear sus reproches y a exigir el reconocimiento de sus derechos, siempre dentro de las convenciones sociales del momento que les tocó vivir.

Es indudable que en las cartas se detecta un sentimiento desbocado que se nutre con la esperanza del regreso del ausente. Sin embargo, a pesar de que pueden parecer a primer vista discretas e inocentes como la respuesta a una gran pasión, en realidad responden a una intención premeditada y calculada: las mujeres exigen por legitimidad la presencia de sus esposos, al menos 
a modo de correspondencia epistolar. Por eso hacen buen uso de algunas estrategias que las llevarán a conseguir su propósito: el de crear una obligación ineludible de la que los esposos no pueden escapar. Mientras que Sereneta y Margaret utilizan la repetición y la insistencia en sus cortas cartas, Héloise, conocedora profunda de la lengua, hace uso de estratagemas retóricas e imágenes sutiles en las suyas.

Es claro que las tres consiguen su empeño, ya que lo tres maridos sucumben a la insistencia de las esposas. Han llegado hasta nuestras manos cartas de Abélard y de John Paston que responden a las de Héloise y Margaret. El caso de Ramón de Tous no es diferente. A pesar de que no tenemos ninguna de sus cartas, sabemos que en algún momento respondió a Sereneta. Ella misma lo dice el 3 de junio de 1374: "he rebuda una letra vostra qui fou feta a XXI 272 de maig, de la cual he aüt gran pler com he sabuda vostra bona sanitat [...]" (407). Se puede afirmar que cada una de las esposas recupera la presencia de su amado en el texto escrito para mantenerlo siempre con ella, porque como bien dice Linda Kauffman la letra escrita es un artefacto inseparable de la necesidad que el individuo tiene de comunicarse (Kauffman, Discourses, 17). Por esta razón, las cartas se convierten en una declaración de amor y a la vez en un documento legal, que obliga a los ausentes a reconocer sus vínculos y obligaciones. Es imperativo reiterar que para las tres mujeres estudiadas el vínculo que crea las obligaciones más profundas es del amor.

\section{BIBLIOGRAFÍA}

Abélard, Pierre, Opera, ed. de Victor Cousin, Hildesheim: Georg Olms, 1970.

AbÉlard, Pierre, Lamentations, Histoire de mes malheurs, Correspondance avec Héloise, trad. de Paul Zumthor, Paris; Babel, 1992.

Abélard, Pierre y Héloise, The Letters of Abélard and Héloise, trad. de Betty Radice, London: Penguin, 1974.

Blamires, Alcuin (ed.), Woman defamed and woman defended: An anthology of medieval texts, Oxford: Clarendon Press, 1992.

Braudel, Fernand, Civilization and capitalism $15^{\text {th }}-18^{\text {th }}$ century. The structures of everyday life, t. I, trad. de Sian Reynolds, New York: Harper and Row, 1979.

Cixous, HÉLÈne, Entre l'écriture, Paris: Des femmes, 1986.

Deyermond, Alan, "Letters as autobiography in late Medieval Spain", Biographie et autobiographie, Razo, 10, 1990, 33-42. [Nice: Centre d'Études Médiévales, Université de Nice]

Dronke, Peter, Women writers of the Middle Ages: A critical study of texts from 
Perpetua (203) to Marguerite Porete (1310), Cambridge: Cambridge University Press, 1984.

Erler, Mary y Maryanne Kowaleski (eds.), Women and power in the Middle Ages, Athens, Georgia: University of Georgia, 1988.

FERrante, JoAn M., To the glory of her sex: Women's roles in the composition of medieval texts, Bloomington: Indiana University Press, 1997.

Finke, LAURIE, Feminist theory, women's writing, Ithaca: Cornell University Press, 1999.

Fonquerne, Yves-René y Alfonso Esteban (eds.), La condición de la mujer en la Edad Media: Actas del coloquio celebrado en la Casa de Velázquez, del 5 al 7 de noviembre de 1984, Madrid: Casa de Velázquez-Universidad Complutense, 1986.

Kamuff, Peggy, Fictions offeminine desire: Disclosures of Heloise, Lincoln: University of Nebraska Press, 1982.

KaUfFMAn, Linda, Discourses of desire: Gender, genre, and epistolary fictions, Ithaca: Cornell University Press, 1986.

Kelly, Henry Ansgar, Love and marriage in the age of Chaucer, Ithaca: Cornell University Press, 1975.

Paston, Margaret, The Paston Letters, ed. de Norman Davis, Oxford: Oxford University Press, 1983, 4 -5, 13-14, 21, 34-36, 55.

Pitts, Brent (trad.), The fifteen joys of marriage, New York: Peter Lang, 1985.

Radice, Betry, “The French Scholar-Lover Heloise”, en Katherina M. Wilson (ed.), Medieval Women Writers, Athens, Georgia: University of Georgia Press, 1984.

Tous, Sereneta DE, “Cartes d'una Catalana del s. XIV al seu marit”, en Miscellania Aramon i Serra en el seu setante aniversari, IV, Barcelona: Curial Edicions Catalanes, 387-419.

Tuchman, BARbara W., A distant mirror: The calamitous $14^{\text {th }}$ Century, New York: Ballantines Books, 1979.

Wilson, Katharina, Medieval women writers, Athens, Georgia: University of Georgia Press, 1984.

Woolf, Virginia, “The Pastons and Chaucer”, The common reader: first series, London: Hogarth Press, 1925, 13-38.

Medievalia 50, 2018, pp. 261-273 
